\title{
The red eye
}

\author{
Jason Noble MD, John C. Lloyd MD
}

Most patients with red eye have a benign or self-limited condition and do not require referral to an ophthalmologist

Conjunctivitis (usually viral), blepharitis, small corneal abrasions, dry eye and subconjunctival hemorrhage account for most cases of red eye seen in primary care.

\section{The initial examination of the eye includes three main components}

The initial examination includes checking visual acuity and pupillary light reflexes, and gross examination of the anterior segment with a penlight or slit lamp. It should be performed without fluorescein. If a corneal epithelial defect, such as a corneal abrasion, is suspected, fluorescein dye and a cobalt blue light will highlight the lesion. A corneal ulcer will also be detected with fluorescein, but a whitish corneal opacity will be visible before use of the dye. A portable tonometer accurately measures intraocular pressure and is useful in assessing suspected acute angle-closure glaucoma. ${ }^{3}$ If tonometry is unavailable, the presence of equal, round, reactive pupils essentially rules out acute angleclosure glaucoma. $^{2}$

\section{Key questions provide clues to the diagnosis}

Ask about decreased vision, pain, lacrimation or discharge, photosensitivity and perception of coloured haloes. Patients should also be asked about use of contact lenses, trauma or chemical injury, and past ocular history. A relevant dermatologic and rheumatologic review of symptoms may help determine whether the ocular findings are related to a systemic condition. If the pain is sharp or has a "foreign-body sensation," it suggests a problem involving the ocular surface. A dull, deeper pain with reduced vision and coloured haloes may indicate acute glaucoma. Discharge and lacrimation often occur with conjunctivitis. Photosensitivity may occur with any inflammation of the ocular surface, as well as with iritis. Recurring redness may indicate either iritis (usually unilateral and associated with photophobia) or allergic conjunctivitis (usually bilateral, with a seasonal pattern, and associated with itching and atopy). ${ }^{2}$ Common presentations and causes of red eye are listed in Appendix 1 (www.cmaj.ca/cgi/content/full/cmaj.090379/DC1).

\section{Red-flag symptoms or signs indi- cate urgent referral to an ophthal- mologist}

Red flags for referral are a history of severe pain, visual loss, marked pain or decreased vision with the use of contact lenses, trauma, chemical injury and recent eye surgery. On examination, signs for concern include decreased visual acuity, pupil irregularity, sluggish pupillary reaction to light, corneal opacification, hyphema or hypopyon, and elevated intraocular pressure. ${ }^{2,4}$ Be especially alert when a patient has unilateral redness. Patients with red-flag symptoms or signs require immediate referral to an ophthalmologist. ${ }^{2}$ Patients without red-flag symptoms or signs may be referred nonurgently (one to three days) if there are continuing concerns. Patients who wear contact lenses should be instructed to stop wearing the lenses immediately.
CMAJ invites submissions to "Five things to know about ..." Submit manuscripts online at http://mc.manuscriptcentral.com/cmaj
Topical steroids should not be routinely prescribed by nonophthalmologists for acute red eye

Topical steroids may exacerbate certain infections, including herpetic keratitis and corneal ulcers. ${ }^{2}$ Long-term use can cause cataracts and glaucoma. Herpetic keratitis should be considered if a dendritiform pattern is visible on the cornea. People who wear contact lenses are at increased risk for corneal ulcers.

\section{References}

1. Nash EA, Margo CE. Patterns of emergency department visits for disorders of the eye and ocular adnexa. Arch Ophthalmol 1998;116:1222-6.

2. Mahmood AR, Narang AT. Diagnosis and management of the acute red eye. Emerg Med Clin North Am 2008;26:35-55.

3. Robinett DA, Kahn JH. The physical examination of the eye. Emerg Med Clin North Am 2008;26:1-16.

4. Wirbelauer C. Management of the red eye for the primary care physician. Am J Med 2006;119:302-6.

Competing interests: None declared.

This article has been peer reviewed.

Affilaitions: From the Department of Ophthalmology and Vision Sciences, University of Toronto, Toronto, Ont.

Correspondence to: Dr. Jason Noble, jason.noble @utoronto.ca

CMAJ 2011. DOI:10.1503/cmaj.090379 